\title{
Influence of Social Interaction on Workplace Motivation and Efficiency of Instructors: An Exploratory Case Study about an Online University in Pakistan
}

\author{
Dr. Muhammad Abid Malik \\ Assistant Professor \\ Virtual University of Pakistan \\ m_abidmalik7@yahoo.com \\ Sameen Azmat \\ Instructor \\ Virtual University of Pakistan \\ Sadia Bashir \\ Virtual University of Pakistan
}

\begin{abstract}
This study investigates the level of social interaction, its determinants and influence on the instructors' motivation and work efficiency in an online university in Pakistan. Exploratory case study design has been used for this purpose. Data was gathered through participant observations and one-to-one interviews. Ten interviews were conducted from instructors belonging to four different departments. Observations were carried out for a period of one month. The study revealed that in the online university, level of social interaction was lower than a traditional one. Instructors pointed out various reasons behind it including high workload, seating arrangements, and attitude of some of the heads. Even when they had free time and opportunities, most of the them preferred browsing through the internet or chatting with their fellows through computers. It appeared that the online culture and intense human-computer interaction had made them addicted to machines. Almost all the instructors agreed that higher and better level of social interaction would improve their job motivation, work efficiency and institutional attachment. They suggested more relaxed environment, trips and social gathering, workshops and conferences involving all the departments, sports week for the faculty members, and facilities like canteen and staffroom for improved social interaction and work experience.
\end{abstract}

Keywords: Social Interaction, Online Education, Motivation, Work Efficiency, Distance Education, Workplace Environment.

\section{Introduction}

Social interaction means how a person communicates with, reacts to or relates with the people around him or her. Aristotle in his famous book Politika said, "Man is by nature a social 
animal” (Aristotle as cited by Vinciarelli, Pantic, Heylen, Pelachaud, Poggi, D'ericco, \& Schroeder, 2012). Human beings tend to thrive in an environment where they can have social communications, interactions and relationships. Research has proved that positive and sociable environment not only makes the employees happy, but also increases their motivation and work efficiency (Edem, Akpan \& Pepple, 2017). Stiglitz, Sen and Fitoussi (2009) said that identity and social interactions influence both the quality of one's life and the work. People usually spend six to nine hours per working day at their workplace. That substantial amount of time not only helps them financially, but also in building social network. A report published in Geneva in 2019 found that" work is not only the main source of income for most people, but also an activity which provides opportunities for social interaction and integration" (Euro Found and International Labor Organization, 2019).

Increasing use of technology has changed the workplace environment a lot. Whereas previously people would interact and talk to one another at workplace face-to-face, now they either interact with the machines or through them (Nickerson, 1976; Bench-Capon \& McEnery, 1989). This trend can be observed more commonly in organizations with computer based work. In an online educational institution, for example, teachers would usually sit silently and interact with or through the computers. Research points out that teachers teaching through online medium have a lot less visual interaction than those working in conventional ones (Joy, 2004).

Although, there has been a lot of research about the social interaction and its impact on employees' mood, motivation and work efficiency (Cammann, Fichman, Jenkins, \& Klesh, 1983; Karau \& Hart, 1998; Snyder \& Stukas, 1999; Sözbilir, 2018); most of such research has been about traditional or conventional organizations. Similarly, despite a lot of research been carried out about online and distance learning; very little has been conducted from sociological perspectives (Heath, Knoblauch \& Luff, 2000). This paper tries to reduce some of the aforementioned research gaps by conducting an exploratory case study about the level of social interaction in an online university, its determinants, and how it influences the motivation and work efficiency from the perspectives of the instructors.

\subsection{Research Objectives}

Main objectives of the study were to:-

1. find out the level of social interaction in an online university.

2. identify the determinants behind it. 
3. explore the influence of social interaction on instructors' workplace motivation and efficiency.

\subsection{Significance of Study}

This study is one of the first one investigating the level, determinants and role of social interaction in an online university. As such, it would help to increase the awareness about the importance of social interaction in an online university, and challenges about it. It would also suggest ways to improve it.

\section{Literature Review}

Motivation is defined by Certo and Certo (2006) as "the inner state that causes an individual to behave in a way that ensures the accomplishment of some goals" (Certo \& Certo, 2006). Motivation can be intrinsic and extrinsic. Extrinsic motivation is the drive to achieve desired outcomes. These drivers or motivating factors like external rewards, benefits, punishments, or obligations are different from routine work or activity (Essam \& Al-Ammary, 2013).

Positive workplace environment and social interaction are two of such factors. They are likely to lead to higher extrinsic motivation and work efficiency (Chandrasekar, 2011; Leblebici, 2012). Employees' morale can be influenced both positively and negatively by the workplace environment. Workplace environment can play a major role in the performance and productivity of an employee (Edem, Akpan \& Pepple, 2017). Positive social interaction improves workplace environment, and boosts one's motivation, work efficiency and organizational attachment. The negative ones, on the other hand, have adverse effects. Venkataramani, Labianca and Grosser (2013) said, "When individuals have more negative relationships with coworkers, they might experience negative moods, emotions and other adverse outcomes such as social ostracism, hindrance, and undermining” (Venkataramani, Labianca, \& Grosser, 2013).

Positive social interaction not only improves and strengthens one mentally, emotionally and psychologically; but also has positive impact on one's physiology. Human physiological system is considered highly responsive to positive social interactions. Heraphy and Dutton (2008) pointed that out by saying that positive social interactions also affected one physically. It is because 
one's physiological system is directly and highly affected by one's mental, emotional and psychological conditions.

Social interaction is not only one of the most important factors that determine the quality of workplace environment, it also has direct influence on employees' performance (Reis \&Gable, 2002). Social exchange theory (Blau, 1964) and the relational systems perspective (Kahn, 1998) indicate that satisfaction level of the employees is highly influenced by the relational systems in which they work. Those relational systems function as a potent barrier against negativity, jolts, trauma and other factors that might mitigate or even eliminate organizational attachment (Burt, 2001; Mitchell \& Lee, 2001). If one is content with social relationships, one expects and believes to be treated with appreciation, support, compassion, respect and positivity by the colleagues (Cammann, Fichman, Jenkins, \& Klesh, 1983). Social interaction also has indirect effects. It is one of the reasons why employees' salaries and workload depend on their co-workers' even when they work independently and separately (Cornelissen, 2016).

Reis and Gable (2002) focused their research on social interaction at workplace. They came to the conclusion that positive social interaction is appetitive which brings rewarding and desired outcomes. On the other hand, negative one is aversive, bringing undesirable, unwelcoming and unpleasant outcomes (Reis \& Gable, 2002).Meda and Vendramin (2017) came to the similar conclusion. They found that working in an environment with high level of social interaction or caring workmates mostly turns out to be beneficial. Seppala and Cameron (2015) echoed similar findings. Venkataramani, Labianca and Grosser (2013) also backed this point. They said, "Social networks influence a broad range of important outcomes for employees, including their performance and career progression (Venkataramani, Labianca, \&

Grosser, 2013).

Dynamic and forward-looking organizations strive to enhance the work and workplace experiences of their employees in order to improve their emotional attachment and work efficiency (Venkataramani, Labianca, \& Grosser, 2013). Positive and improved social interaction at workplace is thus essential for a thriving and vibrant organization. Online institutions, especially educational institutions have much different type and level of social interaction at workplace, but it has not captured the attention of the researchers that much. This study investigates social interaction in an online university to reduce some of those gaps. 


\section{Research Methodology}

\subsection{Methodology}

Case is a "specific, unique, bounded system" (Stake, 2000) which can be an individual, organization, system, city or even a country. The case understudy perfectly meets these parameters. Online university is a bounded system which is specific and unique especially in the context of Pakistan as most of the universities are conventional. As the purpose of the study is to investigate the situation of social interaction at a specific place (an online university), find out the determinants, and explore its influence on the instructors' motivation and work efficiency; exploratory case study method is used. Seaton and Schwier (2014) also used exploratory case study in a similar type of research.

\subsection{Sampling and Recruitment of Participants}

The intent of this investigation was to gather information pertaining to the social interaction in an online university, and how it affected the motivation and work efficiency of the instructors over there. Consequently, research participants were the instructors of an online university in Pakistan. Purposive sampling was used for this study. In qualitative research, the number of participants is not predetermined as the objective is to reach data saturation (Patton, 2002). It was felt that data saturation was reached after eight interviews; still two more interviews were conducted to ensure it. Participants were selected from four different departments (mentioned hereafter dep1, dep2, dep3 and dep4). In order to have gender parity, five male and five female instructors were selected.

\subsection{Research Tools and Data Collection Techniques}

Patton (2002) suggested some tools for case study. Keeping in mind the nature of the research and the context, observations and interviews were selected for data gathering. Context sensitivity is of paramount importance in qualitative research (Patton, 2002). To understand the context directly and better, participant observations were carried out for a period of one month (twenty working days). Every observation was four to five hours long. Observation data was collected qualitatively through field notes.

Interviews started two weeks after the start of observations, and some of the interview questions were based on the findings of the observations. Semi-structured, face-to-face interviews 
were employed as they give the researchers an option to probe further. An interview guide was developed by the researchers with nine main questions. It was shown to two qualitative researchers for content validity. During the interviews, further probing questions were asked when needed. Interviews were mostly carried out at the instructors' workplace. On average, one interview took twenty seven minutes. It took almost one month to conduct ten interviews. All of the interviews were audio recorded using cellular phones.

\subsection{Data Analysis}

Observation notes were analyzed to look for general pattern and incidents relevant to the study. Coupled with interview data, they helped in getting a more comprehensive picture. As the interviews were limited in numbers, no qualitative data analysis software was used. Qualitative data analysis was done using MS Word. First of all, the interviews were transcribed. They were highlighted with different colors to discern them when put together. Later different interviews were put together under key themes i.e. research questions (situation of social interaction at the current workplace, determinants behind that, its influence on the instructors' motivation and work efficiency, ways to improve etc). Those themes were individually coded, which were put into emerging categories. Finally, the categories were merged or deleted to make them more vivid. Verbatim quotations were also used frequently as often the arguments and opinions could not be conveyed through key words or categories (Corden \& Sainsbury, 2005, 2006).

\section{Findings and Analysis}

Observational and interview data was collected and analyzed. Observations findings were used to look for general pattern and important incidents. Interview data was analyzed based on the main research objectives. Data integration was done at discussion level:-

\subsection{Observation Findings and Analysis}

The first thing that was observed was the overall setting and seating arrangement. The instructors were mainly seated in an open hall which was surrounded by cabins. Those cabins were usually reserved for administrative position holders (HODs, Deans etc.). They were big enough to accommodate couple of tables, and two to four chairs. Some of the cabins were shared by two persons. 
The instructors and lecturers sat in the hall in the middle. That hall had three columns of workstations. The workstations with the walls, and some in the middle had dividers. Workstations on the sides (with the wall) were in the configuration of four with two persons sitting side by side (with their workstations partitioned by the chest height dividers) and other two behind their backs. The workstations in the middle were in square shape with four persons sitting on each side. That would mostly allow the faculty members to focus on their work without disturbance. As the research was about instructors, the observations were focused upon the ones sitting in the hall.

It was observed that the instructors worked from 8 a.m. to 4 p.m. or 9 a.m. to 5 p.m. Most would leave for lunch from 1 p.m. to 2 p.m. They sat on their seats most of the time and focused on their systems. Even when they appeared free, they would mostly focus on the computer by reading newspapers or some other recreational materials. Interestingly, it was observed that they became so engrossed into the computers that when they had to talk to a person sitting a few meters away from them, they would often do it through Skype. Generally, a person left the seat two to four times a day for a period of 3 to 10 minutes for each time.

Another interesting point was that even on the same floor, the situation varied from department to department. In some departments, the situation appeared more relaxed and liberal while in others it appeared to be more strict and controlled. Some departments would gather to celebrate birthdays etc. quite regularly while others would be a lot more subdued and reserved. It could only be revealed through interviews if those differences were due to their own choice (agency) or external factors (social structure).

There was one type of incident that occurred a few times (most frequently in two departments and almost never in others) that needs mentioning. It was observed that the instructors belonging to a department would gather together and talk. Then someone would spot the head coming and whisper, "Oh, .... is coming." Upon hearing that, everyone would panic and rush back to their seats to stare at the screens.

\subsection{Interview Data Findings and Analysis}

Interview data was divided under the key research questions, and analyzed. The findings and analysis of this data is as follows.

\subsubsection{Interviewees' Information}

To get an idea about the interviewees, their information is given in the table $\mathrm{i}$. It is worth noting that rather than asking specific age, five age groups were created i.e. group 1 (20-30 years), 
group 2 (31-40 years), group 3 (41-50 years), group 4 (51-60 years), and group 5 (more than 60 years). Participants were asked to tell which specific age group they belonged to. Similarly, experience at the current online university was divided into six groups: group 1 (up to 1 year), group 2 (2-3 years), group 3 (4-6 years), group 4 (7-9 years), group 5 (10-12 years), and group 6 (more than 12 years)

Table 1. Interviewees' Information

\begin{tabular}{lcccc} 
& & Age & Experienee \\
\hline P1 & M & 2 & dep 2 & Group \\
P2 & F & 2 & dep1 & 3 \\
P3 & M & 2 & dep1 & 3 \\
P4 & F & 2 & dep2 & 5 \\
P5 & M & 2 & dep2 & 4 \\
P6 & F & 2 & dep4 & 4 \\
P7 & F & 1 & dep1 & 4 \\
P8 & M & 2 & dep3 & 5 \\
P9 & F & 2 & dep1 & 3 \\
P10 & M & 2 & dep2 & 3 \\
\hline
\end{tabular}

\subsubsection{Social Interaction at Previous Workplace}

The first key question asked from the instructors was about the level of social interaction at their previous workplace. For some it was their first job or they had been working as visiting faculty members. As a result, they could not say much about it. P8 said that the social interaction at the previous workplace was "almost none". P9 who worked as visiting faculty member earlier said that as visiting faculty member, she had "no much interaction". She said that she would go to the university, take lectures and then simply come back. P1 said that his experience at the previous workplace was not pleasant. He said that there was "so much politics". He further said that 
although, people would be socially interactive, but most of that would be within their groups. Also the interaction was not positive or conducive to work.

Most of the participants (P2, P3, P4 and P5) said that the social interaction at their previous workplace was quite frequent and good. P2 said, “....all teachers were communicating with each other. They were not bound for anything". P3 spoke in the same way, saying that it was "great actually". These instructors also thought that the social interaction at previous workplace was better than the current one.

\subsubsection{Social Interaction at the Current Workplace}

One of the most important questions was about the social interaction at their current workplace (online university). There were two main questions asked in this one: social interaction within the department, and social interaction with other departments. Although, departments were not physically divided; it could tell if the situation within different departments varied. That could indicate how much of the situation was due to overall university policies and practices or overall online culture; and how much due to departmental environment. Social interaction with other departments would indicate overall university environment and culture.

Some participants pointed out that the situation in different departments was different. P9 said, "In some departments there is less interaction. There are different departments, different level in each department".

P3 and P7 who belonged to dep1 reported that the social interaction within their department was a lot less than desired. P3 said that social interaction was "very little within one's own department". He described it in these words, "I tried to be social (with) some people, but it is very difficult over here." Overall instructors belonging to dep1 were not very satisfied with the level of social interaction, and believed that it should have been better.

Situation in dep2 appeared a lot better and positive with most of the participants from that department appreciating the level of social interaction within their department. P1 called it "more than enough" while P5 said that "social interaction is good here". The instructors generally believed that not only was the social interaction strong in their department, but they were also 
working together like a cohesive unit. P10 put that in these words, "We have really good bonding here and we are living like a family and we use to have parties and events".

P6 and P8 who belonged to dep4 and dep3 respectively also showed their overall contentment with intradepartmental situation. P6 while talking about the colleagues said, "good company here". P8 while saying that the situation could have been much better, stated that the situation was "still okay here".

Interestingly while most of the participants generally showed contentment with the intradepartmental social interaction, their opinion about interdepartmental one was not that positive. It seems that despite not having any physical walls between the departments, there were unseen ones that were keeping them apart.P7 said that it was "next to nothing" while P4 called it "very less". P8 said that the interdepartmental interaction especially was not that frequent, but it was "very much needed". P9 mentioned how a person had been moved to other floor because of talking "too much" with an instructor from other department.

Some of the participants pointed out that the situation had been improving gradually over the years. P1 said that the situation had been improving gradually. P3 especially pointed out the role of QEC (Quality Enhancement Cell) in that regard. He said, "For the last couple of years, QEC has been very proactive in organizing activities for faculty members. There have been many trips, seminars and other gatherings. Things have improved recently, and now there is more of a feeling of cohesiveness." It showed university level effort to improve the situation in this regard.

\subsubsection{Determinants behind the Current Level of Social Interaction}

The participants were first asked about the determinants behind lower level of social interaction at the online university generally, and then about some of the more significant factors specifically. One of the most frequently reported reason was about the work pressure. Participants time and time again described how the workload in an online university was tougher than a conventional one. P3 said that compared to a conventional university where one had three to four lectures in a week; in an online university one had "lectures all the time". He further added that in online system, one has to update and sometimes even develop handouts (something equal to a book), check MDBs (Moderated Discussion Board) and GDBs (Graded Discussion Board), update exam and quiz bank, prepare assignments, check assignments and papers, and answer to the 
students' queries through email and Skype.P7 further elaborated how something that can be done in five minutes in face-to-face mode, may take many hours over a stretch of days in online mode. She said,

"For example if I am with research project students, I can talk to them and finalize the topic and research plan in half an hour; but in online, even little things become major issues when explained through emails or even phone calls," she further added, “...especially explaining something like SPSS becomes a challenge. Even basic things..., sometimes they cannot pick, it takes hours.”

P9 agreed to it saying that "demand of work which doesn't allow us to interact". P4 further said that the workload was "the actual reason basically" behind this level of social interactions. P6, on the other hand said that the working environment was similar everywhere, and it was more to do with how one managed one's work.

Another reason that came to the forefront was the dependency on the computer, and online culture. P4 explained how reliance on the computers had made them "physically lazy". She said, "We are sitting all the time, and sometimes it feels hard to move so even when we want to talk to a friend sitting nearby. We do not move, we use computers". Some instructors also pointed out that despite having free time and opportunities, most prefer sitting and searching through the internet than moving to and talking to the people. P7 said that most were "addicted to" computers.

When it came to the attitude from the higher authorities, opinions were more divided. It is important to note that the opinions were not taken about their own heads only, but about all. A majority of them pointed out pressure from higher authorities especially at HOD level to "mind your own work". P3 said that some HODs like to keep the people "under their thumb". P7 said that some "bosses minimize the social interaction with other departments". Many, on the other hand, said that there was no pressure from their heads. Some said that they "actually encouraged it". P10 specifically named some heads who were very supportive and cooperative, and went "beyond their professional responsibilities to motivate and buck up their team members". He specifically mentioned one faculty which he said was "outstanding" in research output, and it was mostly due to the "cordial, supportive and learning environment" within the faculty.

Another point that was mentioned by a few instructors was the seating arrangements. Some tried to justify the heads' decisions to discourage social interaction and communication due to the 
working environment. P3 said, "Look, how everyone is sitting. It is basically a hall with people sitting quite close to one another. If someone moves around or speaks too much, it would definitely disturb others. It is different from conventional universities where people have their own personal space. In most of the cases, they have their own cabins, or maximum two people share a room." P2 also said that due to this open environment, "everyone is observed by everyone". Some would note what others are doing and report to different people. She further added that the lack of privacy increased the pressure on the instructors to "look busy".

Another question was if it was a university policy that the instructors would not mingle up that much. Instructors almost unanimously disagreed to it. P7 said, "Official policy of the university is not like this". Some stated that it was more of the culture that had been established over the years.

Most of the participants (P1, P3, P4, P5, P6, P7, P9 and P10) said that they would have preferred higher level of social interaction with more vibrant and interactive environment.

\subsubsection{Influence of Social Interaction on Workplace Motivation and Work Efficiency}

Before talking about the influence of social interaction on the workplace motivation and work efficiency; participants were first asked if and how much of social interaction at workplace was good. Almost all the participants agreed that high level of social interaction at workplace was better as it decreased work pressure and improved institutional attachment. They also pointed out that it should be positive and not overtake the work efficiency. P3 said, "over doing of everything is bad". He further added that it should be "positive and not rife with politics".

All of them agreed that social interaction by and large increased the workplace motivation and work efficiency. P4 said that social interaction "has an effect on the moods and the motivation of the employees". Most of them illuminated how social interaction at workplace increased institutional attachment which made the employees work with passion and heart rather than taking it as a burden. P1 said, "if you are attached to your workplace, you love to come, and work better". P6 said that social interaction "changes our mind, and it affects positively".P10 explained the links among social interaction, job motivation and workplace efficiency in this way, "Social interaction improves your mood. If your mood is good, your motivation is high then obviously it enhances your efficiency as well'.P5 indicated how positivity of social interaction may help mitigate workplace anxiety, pressure and tension. He said, "Of course if you have very good friends you 
will no longer embrace with tensions, depressions; you have good circle of friends then they will help you have a jolly mood". Of course, it is not about having good friends only, but also being able to interact with them freely and frankly.

P3 thought that motivation was even more important than the ability when it came to work efficiency. He said,

"When you are talking about work efficiency it comes from two things : your ability and capability, and how motivated and passionate you are. I have seen people who are very capable but they are not motivated. their work efficiency is very low. I have seen people with less ability, but they are highly motivated and they are able to perform better".

P8 thought that motivation was "personal matter", but he also acknowledged that if the environment was good with some social interaction; a person could "work better".

\subsubsection{Suggestions to Improve Social Interaction in an Online University}

Instructors were specifically asked to suggest ways to improve social interaction in an online university with special reference to their current workplace. Their suggestions could be divided into three categories: policies and practices related suggestions, activities related suggestions and infrastructure related suggestions,

Although there seemed to be no issue with any of the university policy, three of them talked about the practices and approach. Some suggested that the management should open up and encourage interdepartmental discussions and interactions. P7 said that "people should be given some kind of freedom and flexibility". P3 said that the University had one lunch break. If it could also give two more breaks for half an hour each on either side of the lunch, that would help a great deal. He said,

"There is lunch break, but most of the male staff members go out to nearby restaurants for lunch. If they just go out, take lunch and come back; the whole hour is gone. Two additional breaks would allow the people to stay inside the campus, and interact with one another."

Many of the instructors said that online universities need more gathering and social activities due to their overall culture and environment. They suggested many events that could help 
in this regard. P8 said that "some seminars, conferences to find common interest between departments, sports activities, lectures on Islamic topics" could facilitate. P10 pointed out that although there were conferences; but in most of the cases, they were organized by one specific department. He said, "Conferences could be arranged by involving persons from different departments" P6 said that there had been sports week, but they were primarily for the students, and faculty members only had to perform duties. She said that there could be a sports week for faculty members exclusively. This could allow them to mix up and socially interact. Many also suggested trips and tours. They also pointed out how the tours and integration camps by the University had helped in this matter over the last year or two.

The instructors also gave suggestions about infrastructure that could improve social interaction and the working culture. P1 said that if they could have their own purpose built campus like traditional universities, situation could be much better. P3 said that "some kind of common room, some kind of retiring rooms, canteen or small ground so people can go out and walk" should be there. It would help the faculty members in social interaction and would improve their motivation level. These points were repeated by many of them.

\section{Discussion}

The study investigated the level, determinants and influence of social interaction on instructors' motivation and work efficiency in an online university. It is generally assumed that there is more social interaction in conventional universities. By interpreting views of the participants, it can be concluded that social interaction at work place is higher in conventional universities due to their face to face model and culture. Joy (2004) also pointed out the same. Interestingly, those who came from conventional educational institutions thought the same; while for those who came from software houses or online organizations, situation was the same or even better.

Most commonly cited determinant by the instructors for this comparatively lower level of social interaction was the workload. Instructors said that whereas in a conventional system, a teacher may have to show to be there for three to four lectures a week (for 2 to 3 hours per lecture); an online instructor especially in asynchronous mode, has to show to be there a lot more. Conceicao and Lehman (2010) while talking about the increased workload in an online educational institution, 
said that the faculty members had "to create a sense of presence" all the time (Conceicao \& Lehman, 2010, p. 69). Lehman and Conceição (2010) also supported this argument saying that pressure of showing to be there added to the burden in an online system. Instructors also pointed out that in an online system, preparations and management of the materials is a lot more time consuming than in face to face model. Conceicao and Lehman (2010) reported the same thing in their article. Another aspect was seating position and overall environment. Absence of any retiring room, canteen or staffroom also played a part in it. The place where they sat was 8 a.m. to 4 p.m. workplace. Any oral communication or physical movement could disturb the working of the others. Some of participants also mentioned how their heads would discourage especially intradepartmental communications. It can be attributed to their leadership styles. Previous research also showed that some leaders prefer exhibiting controlling behavior (Olham \& Cummings, 1996).

Most interesting revelation was that even when the instructors had free time and opportunities to interact with one another and have face-to-face communication; most either used internet or interacted through online platforms. It was revealed to be due to the influence of computers and online environment. They became so used to interact with or through computers that rather than turning to human beings and talk, they would prefer turning to keys and text. Previous research has also reported this trend of interacting with or through computers (Nickerson, 1976; Bench-Capon \& McEnery, 1989). More often than not very close interaction with computers and similar gadgets drive human beings miles away from each other despite being next to one another. There has been a lot of research indicating how cellular phones are reducing social interaction and face-to-face communications (Suttie, 2013; Jones, 2017; Gladden, 2018), the same pattern can be found in an organization with computer based, online activities and culture.

There is nothing wrong working with machines; but the problems arise when people internalize that mechanical mindset, and start thinking and acting like them. This issue can be more acute at university level where academic faculty members at the lowest rung of the ladder (teachers/ lecturers), have very high level of autonomy, and are supposed to teach creative and critical thinking. If a person is thinking in a linear direction or have mechanical mindset, how can that person develop in him/herself and the students critical and creative thinking.

Role of environment and overall culture cannot be ignored either. Environment is one of the most significant factors in shaping the behaviors and attitudes of human beings (Altinigne \& Bilgin, 2015). When people see others sit silently and looking at the screens, they tend to follow 
the pattern hence creating an environment. This environment influences the people more. The more the people follow it, the more the environment is strengthened. This kind of cycle cannot be broken easily. In an online organization, such environment is usually developed and strengthened over the years, It is only through dedicated and proactive approach that the change may be brought.

It is worth mentioning that nobody thought that it was university policy. Although some departmental heads were mentioned who preferred to keep the things under their thumbs and control their subordinates, it was more of the leadership style and personal traits. This arguments was reinforced by the fact that out of four departments, instructors from one unanimously mentioned head as one of the reasons. In another department, the opinion was neutral. Whereas instructors from other two departments actually said that their heads encouraged such interactions and activities. Some of the instructors also pointed out that the University had been trying to increase social interaction and interdepartmental activities.

All the instructors unanimously agreed to the point that an increased level of social interaction would improve institutional attachment, job motivation and work efficiency. The same has been echoed in numerous earlier studies (Heraphy \& Dutton, 2008; Stiglitz, Sen \& Fitoussi, 2009; Chandrasekar, 2011; Leblebici, 2012; Venkataramani, Labianca \& Grosser, 2013; Edem, Akpan \& Pepple, 2017). Some instructors also expounded how their close interaction with their fellows helped them in hard and torrid times. Meda and Vendramin (2017) also talked about the role of caring workmates and positive environment in overcoming hardships and emotional challenges at workplace.

The University and the management have to take a more proactive role to improve it further. Motivating and encouraging role by the leaders can improve the employees' emotional attachment, social interaction and workplace environment (Riggio \& Reichard, 2008).In the same way, a more proactive and positive role by the heads can help a great deal in this regard. Instructors also suggested couple of extra breaks to have more time to relax and interact with others. This is important as in working time if the instructors are moving or talking around, they may disturb the working environment. It is for the very reason that some instructors suggested to have separate common room or canteen. University must arrange either of the two: give extra breaks when they can stay at their working place and interact, or provide separate place where they may go out for a breather and an exchange of words. Another suggestion was to organize more interdepartmental 
activities like workshops, seminar, trips or integration camps which could provide the faculty members from different departments an opportunity to interact and work together.

\section{Conclusion}

The study came to the conclusion that the level of social interaction in an online university is commonly lower than a traditional one. Some of the most important determinants behind it turn out to be higher workload, seating position, working environment and the role of (some of the) heads. Other than role of the heads, all other factors are likely to exist in other online universities as well. One of the most important reasons that is likely to play a major role in reduced level of social interaction in all online universities is continuous interaction with computers. It makes most of the faculty members addicted to the keyboards and screens. Some of them prefer using computers even when they have time and opportunity to talk and interact with the people around them. Despite almost all of the instructors agreeing that the higher level of social interaction not only improves their motivation and work efficiency, but also institutional attachment; improving social interaction in an online university may be tougher than a traditional one. Online universities need to be more proactive and engage their faculty members through different intradepartmental and inter departmental activities. Universities should also provide the faculty members with space and time where they can disengage themselves from the computers, and engage with fellow human beings.

\section{References}

Altinigne, N., \& Bilgin, F. Z. (2015). The Effect of Environmental Attitudes on Environmentally Conscious Behavior of University Students. https:// www.researchgate.net/publication/ 299556038_The_Effect_of_Environmental_Attitudes_on_Environmentally_Conscious_B ehavior_of_University_Students

Bench-Capon, T. J. M. \& McEnery, A. M. (1989). People Interact Through Computers Not With Them. Interacting with Computers, 1(1), 31-38.

Blau, P. M. (1964). Exchange and Power in Social Life. New York: John Wiley

Burt, R. (2001). Attachment, Decay, and Social Network. Journal of Organizational Behavior, 22, 619-643.

Cammann, C., Fichman, M., Jenkins, G. D. J., \& Klesh, J. R. (1983). Assessing the Attitudes and Perceptions of Organizational Members. In Assessing organizational change: A guide to methods, measures, and practices, Seashore, S. E., Lawler, E. E. III, Mirvis, P. H. and Cammann, C. (eds.) pp. 71-138. New York: Wiley.

Certo, S. \& Certo, S. (2006). Modern Management (10th ed.).New Jersy: Pearson Prentice Hall. 
Chandrasekar, K. (2011). Workplace Environment and Its Impact on Organizational Performance in Public Sector Organizations. International Journal of Enterprise Computing and Business Systems, 1(1), 1-19.

Conceicao, S. C., \& Lehman, R. M. (2010). Faculty Strategies for Balancing Workload when Teaching Online. In M. Glowacki-Dudka (Ed.), 29th Annual Midwest Research-toPractice Conference In Adult, Continuing, Community and Extension Education, pp. 69- 75. East Lansing, MI: Michigan State University.

Corden, A. \& Sainsbury, R. (2005). Research Participants' Views on Use of Verbatim Quotations. Social Policy Research Unit. University of York. https://www.york.ac.uk/inst/spru/pubs/pdf/verb.pdf

Corden, A. \& Sainsbury, R. (2006). Exploring 'Quality': Research Participants' Perspectives on Verbatim Quotations, International Journal of Social Research Methodology, 9(2), 97-110, $10.1080 / 13645570600595264$

Cornelissen, T. (2016). Do Social Interactions in the Workplace Lead to Productivity Spillover among Co-workers? IZA World of Labor

Edem, M. J., Akpan, E. U., \& Pepple, N. M. (2017). Impact of Workplace Environment on Health Workers, Occupational Medicine and Health Affairs, 5(2), 1-5.

Essam, S. \& Al-Ammary, J. (2013). The Impact of Motivation and Social Interaction on the ELearning at Arab Open University, Kingdom of Bahrain. Creative Education, 4, 21-28.

Euro Found and International Labor Organization, (2019). Working Conditions in a Global Perspective, Publications Office of the European Union, Luxembourg, and International Labor Organization, Geneva.

Gladden, D. J. (2018). The Effects of Smartphones on Social Lives: How They Affect Our Social Interactions and Attitudes. OTS Master's Level Projects \& Papers. 586.https:// digitalcommons.odu.edu/ots_masters_projects/586

Heaphy, E. \& Dutton, J. (2008). Positive Social Interactions and the Human Body at Work. Academy of Management Review, 33, 137-162.

Heath, C., Knoblauch, H., \& Luff, P. (2000). Technology and Social Interaction: the Emergence of Workplace Studies. British Journal of Sociology,51(2), 299-320.

Jones, I. (2017). The Effects of Mobile Device Use on Social Interactions among college Students. Selected Honors Theses. 85. https://firescholars.seu.edu/honors/85

Joy, D. (2004). Instructors Transitioning to Online Education. Unpublished doctoral dissertation. Virginia Polytechnic Institute and State University, Blacksburg.

Karau, S. J. \& Hart, J. W. (1998). Group Cohesiveness and Social Loafing: Effects of a Social Interaction Manipulation on Individual Motivation within Groups. Group Dynamics: Theory, Research, and Practice, 2, 185-191.

Leblebici, D. (2012). Impact of Workplace Quality on Employee's Productivity: Case Study of a Bank in Turkey. Journal of Business Economics and Finance, 1(1), 38-49.

Lehman, R. M., \& Conceição, S. C. O. (2010). Creating a Sense of Presence in Online Teaching: How to 'Be There' for Distance Learners. San Francisco: Jossey-Bass 
Meda, D. \& Vendramin, P. (2017). Reinventing Work in Europe: Value, Generations and Labour, Palgrave Macmillan, New York.

Nickerson, R. S. (1976). On Conversational Interaction with Computers. In User Oriented Design of Interactive Graphics Systems: Proceedings of the ACM SIGGRAPH Workshop (1976), ACM Press, 681-683.

Olham, G. R. \& Cummings, A. (1996), Employee Creativity: Personal and Contextual Factors at Work, Academy of Management Journal,39(3), 607-634.

Patton, M. Q. (2002). Qualitative Evaluation and Research Methods (3rd ed.). Sage.

Reis, H. T. \& Gable, S. L. (2002). Toward a Positive Psychology of Relationships. In C. L. M. Keyes, J. Haidt, \& M. E. P. Seligman (Eds.), Flourishing: Positive psychology andthe life well-lived, pp.129-160. Washington, DC: American Psychological Association.

Riggio, R. E. \& Reichard, R. J. (2008). The Emotional and Social Intelligences of Effective Leadership: An Emotional and Social Skill Approach. Journal of Managerial Psychology, 23, 169-185,

Seaton, J. X. \& Schwier, R. (2014). An Exploratory Case Study of Online Instructors: Factors Associated with Instructor Engagement. Journal of Distance Education,29, 1-16.

Seppala, E. \& Cameron,. K. (2015). Proof that Positive Work Cultures are More Productive. Havard Business Review. https://hbr.org/2015/12/proof-that-positive-work-culturesaremore-productive

Siritongthaworn, S. \&Krairit, D. (2006). Satisfaction in E-learning: the Context of Supplementary Instruction, Campus-Wide Information System, 23(2), 76-92.

Snyder, M. \& Stukas, A. (1999). Interpersonal Processes: the Interplay of Cognitive, Motivational, and Behavioral Activities in Social Interaction. Annu. Rev. Psychol,50, 273-303.

Sözbilir, F. (2018). The Interaction between Social Capital, Creativity, and Efficiency in Organizations. Thinking Skills and Creativity,27, 92-100.

Stake, R. E. (2000). Case Studies. In N. K. Denzin \& Y. S. Lincoln (Eds.), Handbook of qualitative research (2nd ed.) pp. 435-454,. London: Sage Publications, Inc.

Stiglitz, J., Sen, A., \& Fitoussi, J. P. (2009). Report by the Commission on the Measurement of Economic Performance and Social Progress. https:/ec.europa.eu/eurostat/documents/ 118025/118123/Fitoussi+Commission+report

Suttie, J. (2013). How Smartphones Are Killing Conversation. Greater Good Magazine. https://greatergood.berkeley.edu/article/item/how_smartphones_are_killing_conversation

Venkataramani, V., Labianca, G., \& Grosser, T. (2013). Positive and Negative Workplace Relationships, Social Satisfaction, and Organizational Attachment. The Journal of Applied Psychology, 98(6), 1028-1039.

Vinciarelli, A., Pantic, M., Heylen, D., Pelachaud, C., Poggi, I., D'ericco, F., \& Schroeder, M. (2012). Bridging the Gap between Social Animal and Unsocial Machine: A Survey of Social Signal Processing, IEEE Trans. Affective Comput. 3(1), 69-87. 